\title{
PREVALENCE OF CHRONIC PAIN WITH NEUROPATHIC CHARACTERISTICS IN THE GENERAL POPULATION
}

Didier Bouhassira, M.D, PhD (1,2), Michel Lantéri-Minet, M.D, PhD (3), Nadine Attal, M.D, PhD (1,2), Bernard Laurent, M.D (4), Chantal Touboul (5)

1) INSERM U-792, Boulogne-Billancourt F-92100 France; CHU Ambroise Pare, APHP, Boulogne-Billancourt, F-92100 France; 2) Université Versailles-Saint-Quentin, Versailles F-78035, France; 3) CHU Pasteur, Centre d'Evaluation et Traitement de la Douleur, Nice,

F-06000 France; 4) CHU de Bellevue, Service de Neurologie, Saint-Etienne, F-42055 France; 5) TNS Healthcare SOFRES, Montrouge, F-92129 France

Correspondence to:

Didier Bouhassira

INSERM U-792

Centre de Traitement et d'Evaluation de la Douleur, CHU Ambroise Paré

9, avenue Charles de Gaulle

92100 Boulogne-Billancourt cedex

telephone number: +331490945 56

fax number: +33149094435

e-mail: didier.bouhassira@apr.aphp.fr 


\begin{abstract}
We conducted a large nationwide postal survey to estimate the prevalence of chronic pain with or without neuropathic characteristics in the French general population.

A questionnaire aimed at identifying chronic pain (defined as daily pain for at least 3 months), evaluating its intensity, duration and body locations was sent to a representative sample of 30,155 subjects. The DN4 questionnaire was used to identify neuropathic characteristics.

Of the questionnaires, 24,497 (81.2\%) were returned and 23,712 (96.8\%) could be assessed. 7,522 respondents reported chronic pain (prevalence $=31.7 \%$; [95\% CI: 31.1 $32.3]$ ) and 4,709 said the pain intensity was moderate to severe (prevalence $=19.9 \%$; [95\%Cl: 19.5-20.4]). Neuropathic characteristics were reported by 1,631 respondents with chronic pain (prevalence $=6.9 \%$; $[95 \% \mathrm{Cl}: 6.6-7.2]$ ), which was moderate to severe in 1,209 (prevalence $=5.1 \%[95 \% \mathrm{Cl}: 4.8-5.4]$ ). A higher prevalence of chronic pain with neuropathic characteristics was associated with middle age (50-64 years), manual professions and those living in rural areas. It was more frequently located in the lower limbs and its intensity and duration were higher in comparison with chronic pain without neuropathic characteristics.

This large national population-based study indicates that a significant proportion of chronic pain patients report neuropathic characteristics. We identified distinctive sociodemographic profile and clinical features indicating that chronic pain with neuropathic characteristics is a specific health problem.
\end{abstract}




\section{Introduction}

Neuropathic pain is caused by a lesion or dysfunction of the peripheral or central nervous system (Merskey and Bogduk 1994). It is generally chronic and disabling, and is among the most challenging to treat (Dworkin et al., 2003; Finnerup et al., 2005; Attal et al., 2006). This may be related to the specificities of its pathophysiological mechanisms (Woolf and Manion, 1999; Baron, 2006), but also to its being underestimated, particularly in patients having no definite neurological condition (Harden and Cohen, 2003). There have been considerable advances in the understanding of neuropathic pain syndromes over the last decade (Jensen and Baron, 2003; Woolf, 2004). However, there is a lack of general epidemiological information.

Major causes of neuropathic pain include: diabetes, shingles, spinal cord injury, stroke, multiple sclerosis, cancer, and HIV infection, as well as common conditions, such as lumbar or cervical radiculopathies, and traumatic or postsurgical nerve injuries. The large range of etiologies indicates that the prevalence of neuropathic pain may be high in the general population. This has also been suggested by studies based on cohorts seen in specialized referral centers, which showed that considerable proportions of patients with herpes zoster (Jung et al., 2004), diabetic polyneuropathy (Daousi et al., 2004; Davies et al., 2006); multiple sclerosis (Osterberg et al., 2005), spinal cord injury (Siddall et al., 2003), stroke (Andersen et al., 1995); HIV infection (Hewitt et al., 1997); cancer (Caraceni et al., 1999) and persistent postsurgical pain (Kehlet et al., 2006), suffer neuropathic pain. These studies did not allow estimation of the overall prevalence of neuropathic pain in the general population, but crude estimates in the $1-3 \%$ range have been proposed (Bowsher, 1991; Dworkin et al., 2003; Irving, 2005). 
One major reason for the absence of population-based epidemiologic data on neuropathic pain was the lack of a validated, reliable and simple clinical instrument that can identify the characteristics of neuropathic pain. Recently, we developed and validated the DN4 questionnaire based only on the analysis of the semiological characteristics of pain (i.e. pain descriptors). We demonstrated that a relatively small number of items was sufficient to discriminate pain due to a definite neurological lesion (Bouhassira et al., 2005). Like other symptom-based screening tools vadidated recently (Bennett, 2001; Krause and Backonja, 2003; Portenoy, 2006; Freynhagen et al., 2006a), the DN4 questionnaire has very good discriminative properties for the identification of neuropathic pain characteristics. One of the chief research application of these questionnaires is epidemiological studies (Bennett et al., 2007). A first population-based survey using the Leeds Assessment of Neuropathic Symptom and Signs score (S-LANSS) estimated the prevalence of chronic pain of predominantly neuropathic origin in six family practices in 3 UK cities (Torrance et al., 2006).

Here, we present the results of STOPNEP (Study of the Prevalence of Neuropathic Pain), a postal survey carried out to estimate the prevalence of chronic pain with or without neuropathic characteristics in a large representative sample of the French general population. 


\section{Methods}

The STOPNEP population-based survey was carried out from August to November 2004 by the poll institute TNS Healthcare Sofres. Although no nominative data were recorded, the study was notified to the French personal data processing surveillance authorities (Commission Nationale Informatique et Libertés, CNIL) and was conducted according to the relevant national and European laws and consensus professional guidelines.

\subsection{Subjects}

The survey was conducted among the "Access Santé" permanent polling base representative of the French population. Individuals entered into this polling base are recruited in several ways (face-to-face interviews, mailings, phone calls) to reduce possible risk of selection bias associated with a particular methodology.

A questionnaire was sent to a randomly selected representative sample of 30,155 panellists aged 18 years and over. The representativeness of the sample with respect to the French national population (INSEE, 2002) was checked for sex (2 categories), age (6 categories), socio-professional status (8 categories), region (5 categories) and community size (5 categories). Reminder letters were sent to nonrespondents to increase the response rate.

\subsection{Survey questionnaire}

To ensure maximal response rate, the questionnaire was deliberately simple and short. As well as socio-demographic information, there were only 11 questions concerning pain. The first two questions were used to identify chronic daily pain (question 1: Do you currently suffer with pain every day?; if yes, question 2: Have you had this daily 
pain for at least three months?). The remainder of the questionnaire only applied to participants who responded positively to these two questions; participants responding negatively to the first question represented the control group.

Participants with chronic pain then located their pain from a list of body sites grouped into seven categories (question 3 [several answers possible]) and, if they mentioned several locations, reported the single location of the most troublesome pain (question 4). The remaining seven questions related to the duration, intensity and characteristics of the most troublesome pain. The subjects reported its duration (less than 6 months, between 6 and 12 months, between 1 and 3 years, or more than 3 years). They then specified whether the pain varied in intensity during the day and reported the highest, lowest, and average intensity of pain during the past 24 hours, on three numerical rating scales $(0=$ no pain, $10=$ worst pain imaginable $)$ from the Brief Pain Inventory (Cleeland and Ryan, 1994). Finally, the subjects answered the two questions (including seven items) from the DN4-interview questionnaire (Bouhassira et al., 2005) regarding the characteristics of their pain. A score of 1 was given to each positive item and a score of 0 to each negative item. The total score was calculated as the sum of the seven items. Respondents with a total score $\geq 3$ were considered to have neuropathic pain characteristics, based on our previous study (Bouhassira et al., 2005).

Initially, the DN4-interview questionnaire was validated as a clinician-administered questionnaire. Before starting the present survey, we performed a complementary validation with a group of 84 consecutive patients with chronic neuropathic $(n=49)$ or non-neuropathic $(n=35)$ pain to compare self-administered and clinician-administered forms of the seven-item DN4 questionnaire. The results of the self-reported and clinician- 
administered questions for each of the seven items showed excellent consistency (kappa coefficients of 0.82 to $0.95 ; \mathrm{p}<0.001)$. We also verified the diagnostic properties of the self-administered DN4 questionnaire by calculating its sensitivity and specificity for the independent diagnosis made by expert clinicians. We confirmed the high discriminant values of the self-administered seven-item DN4 questionnaire, in which the sensitivity $(81.6 \%)$ and specificity $(85.7 \%)$ for a cut-off score of 3 of 7 were similar to those observed in our initial study using a clinician-administered version of the questionnaire (Bouhassira et al., 2005).

\subsection{Statistical analysis}

The representativeness of the sample was assessed by using the quota method (Ardilly, 1994). In order to reduce the bias due to the non respondents and present estimations for the French general population, the sociodemographic characteristics of the respondents were adjusted to the structure of the French general population (INSEE, 2002). Computerised weighting was used in our analyses, according to the Raking Adjusted Statistic method, in order to compensate for any stratum under- or overrepresentation (Deville et al., 1993). The observed and weighted sociodemographic characteristics of survey respondents are presented in table 1 . Odds ratios and $95 \%$ confidence intervals $(\mathrm{Cl})$ were calculated and a forward stepwise logistic regression, with all sociodemographic variables entered in the model, was used to assess the association between chronic pain with or without neuropathic characteristics and the sociodemographic characteristics.

Pain intensity scores of 1-3 were considered to indicate mild pain intensity, scores of 4-6 moderate pain intensity, and scores of 7-10 severe pain intensity. Categorical 
variables were described by the relative percentages in the relevant subject groups, 95\% confidence intervals $(95 \% \mathrm{Cl})$ and differences in proportions were compared with the $\mathrm{z}$ test. Continuous variables were described by the mean and standard deviation (SD). All analyses were carried out using SAS software, version 8.2 (SAS Institute). Statistical significance was considered at $p<0.05$. 


\section{Results}

Of the 30,155 questionnaires sent, 24,497 (81.2\%) were returned $(69.3 \%$ after the first mailing and $11.9 \%$ after the reminder) and 23,712 (i.e. $96.8 \%$ ) could be assessed.

\subsection{Prevalence of chronic pain in the general population}

A total of 7,522 subjects, that is a prevalence of $31.7 \%$ [95\% $\mathrm{Cl}: 31.1-32.3]$, reported chronic daily pain for more than three months.

The prevalence of chronic pain according to the sociodemographic characteristics of the population are presented in table 2. The prevalence of chronic pain was higher in women than in men and increased significantly with age. People reporting chronic pain were equally distributed among the geographical areas, although they were slightly fewer in Paris (a large urban community). More retired subjects but fewer managers, middle executives and employees suffered chronic pain.

The mean pain intensity was $4.5 \pm 2.1$ of 10 . About one-third (i.e. $33.9 \%$ ) of respondents reported mild pain intensity (i.e. mean intensity $=1-3$ ), $46.5 \%$ reported moderate pain intensity (i.e. mean intensity $=4-6$ ) and $16.1 \%$ severe pain (i.e. mean intensity $=7-10)$. Thus, the prevalence of moderate to severe chronic pain in the general population was $19.9 \%$ [95\%Cl: $19.5-20.4]$.

\subsection{Prevalence of chronic pain with neuropathic characteristics}

The distribution of the DN4 scores in the study population is presented in figure 1. A total of 1,631 respondents with chronic pain, being a prevalence of $6.9 \%$ [95\% $\mathrm{Cl}$ : 6.6 7.2], had a DN4 score $\geq 3$ and were considered to have chronic pain with neuropathic characteristics (NC). Pain intensity was moderate to severe in almost three-quarters (74.1\%) of these participants $(n=1,209)$, representing a prevalence of $5.1 \%$ [95\%Cl: 4.8 - 
5.4 ] in the general population. Thus, NC were reported by $21.7 \%$ of respondents with chronic pain of any intensity and $25.6 \%$ of respondents with chronic pain of moderate to severe pain intensity.

3.2.1. Socio-demographic profile of respondents with chronic pain with or without NC (table 3).

Chronic pain with NC was more prevalent in women than in men: $60.5 \%$ of respondents with NC were women and increased with age, peaking at 50-64 years. It was more than twice as prevalent in manual workers or farmers than in managers and was more prevalent in rural areas than in large urban communities.

\subsubsection{Comparison of clinical characteristics between pain with or without NC.}

Not only pain description, but also its intensity, duration and location differed significantly between people with chronic pain with NC and those without NC.

All seven sensory descriptors of the DN4 occurred significantly more frequently in the chronic pain with NC group (table 4).

The mean pain intensity during the last 24 hours was slightly but significantly $(p<0.01)$ higher in participants with chronic pain with $N C(5.1 \pm 2.1)$ than in those without NC (4.2 \pm 2.0$)$, suggesting that chronic pain with NC was more severe. This was also supported by significantly more participants with chronic pain with NC reporting a severe mean pain intensity ( $\geq 7$ out of 10 ) and a duration $\geq 3$ years (table 4 ). Variations in pain intensity over the last 24 hours were reported by a significantly higher proportion $(p<0.01)$ of respondents with NC (40.5\%) than respondents without NC (31.6\%).

The location of pain differed significantly between the pain groups. In both groups, the most frequent locations were the lower and upper limbs, the back and the neck. 
However, $42.0 \%$ of respondents with chronic pain without NC reported only one pain location, mostly in the back (40.3\%). This contrasted with the minority $(20.8 \%)$ of respondents with chronic pain with NC who reported only one location, mostly in the lower limbs (40.3\%). Only $5 \%$ of these respondents reported pain only in the back. Most respondents with NC (78.4\%) reported two (38\%) or three (30\%) pain locations. The most common combinations were the back with at least one lower limb (46.8\%) and the neck with at least one upper limb (29.0\%). 


\section{Discussion}

STOPNEP is one of the largest surveys specifically devoted to chronic pain reported in the literature and the first national population-based study on chronic pain prevalence carried out in France.

The strengths of this postal survey were the large size of the sample, its representativeness in terms of sex, age, profession and place of residence and the high return rate of the questionnaire. Our observed point prevalence for chronic pain, defined as daily pain lasting over more than three months, is consistent with previous epidemiological studies. Early studies reported a relatively large range of prevalence rates (i.e. $7-50 \%$ ) that could be explained by methodological disparities (e.g. differences in data collection and/or differences in the definition of chronic pain) (Verhaak et al., 1998; Elliot et al., 1999). However, a series of more recent surveys using similar criteria have consistently reported prevalence rates of between 15 and $25 \%$ for chronic pain of at least a moderate intensity (Andersson et al., 1993; Buskila et al., 2000; Blyth et al., 2001; Eriksen et al., 2003; Rustoen et al., 2004; Breivick et al., 2005). Therefore, the prevalence of $19.9 \%$ for chronic pain of at least moderate intensity in this study, is probably clinically relevant. Our results also indicated that chronic pain is more prevalent in women, older people and those with a lower professional status, which is consistent with previous studies. Thus, our data confirm that chronic pain is highly prevalent in the French general population, as it is in other developed countries.

Our results based on the DN4 questionnaire show a prevalence of neuropathic characteristics of $6.9 \%$ in subjects with chronic pain of any intensity and $5.1 \%$ in those with chronic pain of moderate to severe intensity. A higher prevalence of neuropathic 
characteristics was associated with sex (women), place of residence (rural areas), age (middle-age) and profession (farmers and workers).

Our estimation of the overall prevalence of chronic pain with neuropathic characteristics is close, although slightly lower, to that reported in the only comparable survey carried out in UK (i.e. prevalence rate 8.2\%) (Torrance et al., 2006). A higher prevalence of chronic pain was reported in the British study (i.e. $48 \%$ ), which may be explained by a different definition of chronic pain (including intermittent pain or discomfort) and/or a bias due to the relatively low return rate of the questionnaire (i.e. $52.4 \%)$. However, the proportion of chronic pain with neuropathic characteristics was similar in the two studies. In addition, both studies concluded that neuropathic characteristics were more frequently located in the limbs and were more severe (i.e. higher intensity and longer duration) than pain without neuropathic characteristics. These two population-based surveys carried out in parallel in two different countries indicate that, together with differences in clinical expression, chronic pain with neuropathic characteristics has a specific sociodemographic profile. Thus, it should be considered as a distinct clinical entity that deserves particular attention.

One general limitation of our study is related to the difficulties associated with the definition and diagnosis of neuropathic pain (Max, 2002; Backonja, 2003; Bennett, 2003; Hansson, 2003; Rasmussen et al., 2004). In principle, because of the lack of validated diagnostic criteria, one cannot equate the neuropathic characteristics identified in the present study with neuropathic pain. However, the present data indicate that the neuropathic characteristics identified in the general population are similar to those of patients with chronic pain due to an identified neurological lesion (Bouhassira et al., 
2005), corresponding to the newly proposed category of "definite neuropathic pain" (Rasmussen et al., 2004). Consistent with our previous results (Bouhassira et al., 2005), we found that all the DN4 items were significantly more frequent in the group of respondents with neuropathic characteristics. Importantly, the seven descriptors had frequencies almost identical to those reported in our original validation study. Thus, although the DN4 questionnaire was not formally validated in the general population, the present results strongly suggest that the neuropathic characteristics identified in patients referred to multidisciplinary pain centers are representative of those in the general population. This is also supported by our estimated proportion of chronic pain sufferers with neuropathic characteristics in the general population $(25 \%$ of sufferers of chronic pain of at least moderate intensity), which agrees with previous studies showing that 20 to $30 \%$ of patients seen in pain clinics have neuropathic pain (Bowsher, 1991; Davies et al., 1992; Grond et al., 1996). More generally, the present data suggest that the differences in terms of chronic pain characteristics between patients referred to specialized centers and the general population might be more quantitative (e.g. intensity, duration) than qualitative.

Another limitation of our study is the lack of direct information regarding the aetiology of pain. Like the other recently validated screening tools based on symptoms (Bennett et al., 2007), the DN4 questionnaire allows identification of chronic pain with neuropathic characteristics with a very good specificity and sensitivity, but does not allow identification of its cause. Determining the cause of a neurological lesion requires a complete physical examination, often including electrophysiological testing, laboratory tests, and/or imaging, which are incompatible with large epidemiological studies. Nonetheless, despite the lack of questions specifically related to the pain aetiology in the 
present survey, analysis of the pain locations reported by the participants revealed some interesting results. We found that most respondents with neuropathic characteristics reported more than one pain location. Because pain located in different areas of the body may involve distinct mechanisms, one cannot exclude that a proportion of these participants had a combination of pain with and without neuropathic characteristics (i.e. the so-called "mixed pain"). In the present study we analyzed only the characteristics in one location corresponding to the most troublesome pain. Therefore, one can conclude that respondents with several pain locations presented with at least one chronic pain with neuropathic characteristics, but one cannot conclude regarding the characteristics (neuropathic or not) of pain in the other locations. In any case, our results indicate that the neuropathic characteristics reported by patients with several pain locations are similar to those of patients with definite neuropathic pain in only one location (Bouhassira et al., 2005). Interestingly, this is consistent with the recent results of Freynhagen et al. (2006b) showing that radiculopathies associated with mixed pain syndromes have clinical characteristics similar to those of definite neuropathic pain syndromes. In the present study, the most frequent combinations in participants with neuropathic characteristics, were pain in the lower limbs and the back or in the upper limbs and the neck. These specific distributions might indicate that the neuropathic characteristics we identified in the general population corresponded primarily to lumbar or cervical radiculopathies. This hypothesis, which has to be confirmed in future studies, is consistent with data showing that chronic back and neck pain, which are highly prevalent in the general population (e.g. Andersson, 1999; Deyo and Weinstein, 2001; Webb et al., 2003), are very frequently associated (up to $40-50 \%$ of patients) with neuropathic radiculopathies (Hillman et al., 1996; Kaki et al., 2005; Freynhagen et al., 2006b). 
In conclusion, the present study is an important step towards a general epidemiology of neuropathic pain. Studies are now underway to analyse further the aetiologies of chronic pain with neuropathic characteristics and to determine its natural history, risk factors, comordities (e.g. depression, anxiety, sleep disorders) and its impact on the quality of life and to estimate its cost for the health services.

Acknowledgements: This study was supported by Pfizer France. 


\begin{tabular}{|c|c|c|}
\hline & \multicolumn{2}{|c|}{ Survey respondents } \\
\hline & $\begin{array}{c}\text { Unweighted } \\
\%(\mathrm{~N})\end{array}$ & $\begin{array}{c}\text { Weighted } \\
\%(\mathrm{~N})\end{array}$ \\
\hline \multicolumn{3}{|l|}{ Gender } \\
\hline Male & $46.0(10912)$ & $48.0(11382)$ \\
\hline Female & $54.0(12800)$ & $52.0(12330)$ \\
\hline \multicolumn{3}{|l|}{ Age (years) } \\
\hline$<25$ & $9.5(2245)$ & 15.7 (3723) \\
\hline $25-34$ & $17.9(4232)$ & $16.6(3937)$ \\
\hline $35-49$ & 25.7 (6106) & $26.6(6308)$ \\
\hline $50-64$ & $22.1(5240)$ & $21.1(5003)$ \\
\hline $65-74$ & $15.7(3725)$ & $12.6(2988)$ \\
\hline$\geq 75$ & $9.1(2164)$ & $7.4(1753)$ \\
\hline \multicolumn{3}{|l|}{ Work status } \\
\hline Farmers & $0.6(145)$ & $1.3(308)$ \\
\hline Shopkeepers & $2.0(475)$ & 3.1 (735) \\
\hline Managers & $8.4(1978)$ & 7.7 (1826) \\
\hline Middle Executive & $14.8(3512)$ & $11.4(2703)$ \\
\hline Clerks & $18.5(4389)$ & 16.4 (3889) \\
\hline Workers & $10.3(2450)$ & $14.7(3486)$ \\
\hline Retired & $28.6(6792)$ & $22.2(5264)$ \\
\hline Other non working & $16.8(3981)$ & $23.2(5501)$ \\
\hline \multicolumn{3}{|l|}{ Place of Residence } \\
\hline North & $6.6(1563)$ & $6.8(1614)$ \\
\hline East & $9.5(2264)$ & $9.1(2160)$ \\
\hline Center & $35.1(8332)$ & $36.0(8545)$ \\
\hline West & $13.2(3140)$ & $13.2(3133)$ \\
\hline South & $35.4(8413)$ & 34.9 (3989) \\
\hline \multicolumn{3}{|l|}{ Community Size } \\
\hline Rural ( $\leq 2000)$ & $22.9(5428)$ & $25.2(5974)$ \\
\hline Cities $<20000$ & $17.3(4114)$ & $17.2(4078)$ \\
\hline Cities $<100000$ & $14.0(3329)$ & $12.6(2987)$ \\
\hline Cities >100000 & $29.8(7057)$ & $28.2(6685)$ \\
\hline Paris (10 million) & $16.0(3784)$ & $16.8(3989)$ \\
\hline
\end{tabular}

Table 1: Sociodemographic characteristics of the survey respondents before (unweighted) and after (weighted) adjustment to the structure of the French general population. 


\begin{tabular}{|c|c|c|c|c|}
\hline & $\begin{array}{l}\text { Prevalence } \\
\text { of chronic pain } \\
\%[95 \% \mathrm{Cl}]\end{array}$ & $\begin{array}{c}\text { Unadjusted } \\
\text { Odds Ratio } \\
{[95 \% \mathrm{Cl}]}\end{array}$ & $\begin{array}{c}\text { Adjusted } \\
\text { Odds Ratio } \\
{[95 \% \mathrm{Cl}]}\end{array}$ & $P$ \\
\hline \multicolumn{5}{|l|}{ Gender } \\
\hline Male $^{r}$ & 28.2 [27.6-28.7] & 1.0 & 1.0 & \\
\hline Female & $35.0[34.4-35.6]$ & $1.37[1.30-1.45]$ & $1.41[1.33-1.50]$ & $<0.001$ \\
\hline \multicolumn{5}{|l|}{ Age (years) } \\
\hline$<25$ & 21.0 [20.4-21.5] & $0.40[0.36-0.44]$ & $0.39[0.35-0.43]$ & $<0.001$ \\
\hline $25-34$ & 20.9 [20.3-21.4] & $0.40[0.36-0.43]$ & $0.40[0.36-0.44]$ & $<0.001$ \\
\hline $35-49$ & $25.5[24.9-26.0]$ & $0.51[0.47-0.55]$ & $0.52[0.48-0.57]$ & $<0.001$ \\
\hline $50-64^{r}$ & $40.1[39.4-40.7]$ & 1.0 & 1.0 & \\
\hline $65-74$ & $46.3[45.6-46.9]$ & $1.29[1.18-1.42]$ & $1.20[1.07-1.34]$ & 0.0016 \\
\hline$\geq 75$ & $52.4[51.6-53.0]$ & $1.64[1.47-1.83]$ & $1.52[1.34-1.73]$ & $<0.001$ \\
\hline \multicolumn{5}{|l|}{ Work status } \\
\hline Farmers & $30.8[30.2-31.4]$ & $1.74[1.33-2.27]$ & $1.67[1.27-2.19]$ & $<0.001$ \\
\hline Shopkeepers & $31.3[30.7-31.9]$ & $1.77[1.46-2.15]$ & 1.51 [1.24-1.83] & $<0.001$ \\
\hline Managers $^{r}$ & 20.4 [19.9-20.9] & 1.0 & 1.0 & \\
\hline Middle Executive & 24.8 [24.2-25.3] & $1.29[1.11-1.48]$ & $1.27[1.10-1.47]$ & $<0.001$ \\
\hline Clerks & $27.6[27.0-28.1]$ & $1.48[1.30-1.70]$ & $1.37[1.19-1.57]$ & $<0.001$ \\
\hline Workers & 29.5 [28.9-30.0] & $1.63[1.43-1.87]$ & $1.84[1.61-2.12]$ & $<0.001$ \\
\hline Retired & $46.3[45.6-46.9]$ & 3.36 [2.96-3.81] & $1.54[1.32-1.80]$ & $<0.001$ \\
\hline Other non working & 29.3 [28.7-29.9] & $1.61[1.42-1.83]$ & $1.45[1.26-1.68]$ & $<0.001$ \\
\hline \multicolumn{5}{|l|}{ Place of Residence } \\
\hline North & $33.8[33.2-34.4]$ & $1.05[0.94-1.18]$ & $1.07[0.95-1.20]$ & 0.2 \\
\hline East & $31.2[30.6-31.8]$ & $0.93[0.84-1.03]$ & $1.02[0.95-1.13]$ & 0.7 \\
\hline Center & $31.1[30.5-31.7]$ & $0.93[0.87-1.00]$ & $0.95[0.88-1.01]$ & 0.1 \\
\hline West & 30.3 [29.7-30.9] & $0.90[0.82-1.01]$ & $0.91[0.83-1.00]$ & 0.4 \\
\hline South $^{r}$ & 32.6 [31.1-33.2] & 1.0 & 1.0 & \\
\hline \multicolumn{5}{|l|}{ Community Size } \\
\hline Rural $(\leq 2000)$ & 31.7 [31.1-32.2] & $0.90[0.82-0.99]$ & - & - \\
\hline Cities $<20000$ & 31.9 [31.3-32.5] & $0.92[0.83-1.01]$ & - & - \\
\hline Cities $<100000^{r}$ & 33.9 [33.2-34.5] & 1.0 & - & - \\
\hline Cities $>100000$ & 32.1 [31.5-32.7] & $0.93[0.84-1.01]$ & - & - \\
\hline Paris (10 million) & 29.3 [28.7-29.9] & $0.81[0.73-0.90]$ & - & - \\
\hline
\end{tabular}

Table 2: Prevalence of chronic pain according to socio-demographic characteristics. Unadjusted odds ratio and adjusted odds ratio based on stepwise forward logistic regression. ${ }^{r}=$ reference category. 


\begin{tabular}{|c|c|c|c|c|}
\hline & $\begin{array}{c}\text { Chronic Pain with } \\
\text { Neuropathic } \\
\text { Characteristics } \\
\%[95 \% \mathrm{Cl}]\end{array}$ & $\begin{array}{l}\text { Odds Ratio } \\
\text { [95\% } \mathrm{Cl}]\end{array}$ & $\begin{array}{c}\text { Adjusted } \\
\text { Odds Ratio } \\
{[95 \% \mathrm{Cl}]}\end{array}$ & $P$ \\
\hline \multicolumn{5}{|l|}{ Gender } \\
\hline Male & $5.7[5.4-6.0]$ & 1.0 & 1.0 & \\
\hline Female & 8.0 [7.7-8.3] & $1.21[1.08-1.35]$ & $1.23[1.11-1.43]$ & $<0.001$ \\
\hline \multicolumn{5}{|l|}{ Age (years) } \\
\hline$<25$ & 4.9 [4.6-5.2] & $0.80[0.64-0.90]$ & $0.78[0.63-0.7]$ & 0.02 \\
\hline $25-34$ & $4.2[3.9-4.5]$ & $0.6[0.5-0.8]$ & $0.6[0.5-0.8]$ & 0.004 \\
\hline $35-49$ & $6.4[6.1-6.7]$ & $1.01[0.86-1.18]$ & $1.01[0.85-1.19]$ & 0.94 \\
\hline $50-64^{r}$ & $9.3[8.9-9.7]$ & 1.0 & 1.0 & \\
\hline $65-74$ & $8.4[7.9-8.7]$ & $0.78[0.65-0.93]$ & $0.78[0.63-0.96]$ & 0.02 \\
\hline$\geq 75$ & 9.0 [8.5-9.3] & $0.80[0.65-0.98]$ & $0.80[0.63-1.02]$ & 0.07 \\
\hline \multicolumn{5}{|l|}{ Work status } \\
\hline Farmers & 8.7 8.3-9.1] & $2.21[1.30-3.76]$ & 1.88 [1.09-3.23] & 0.02 \\
\hline Shopkeepers & $6.6[6.3-6.9]$ & $1.65[1.08-2.53]$ & $1.46[0.95-2.25]$ & 0.08 \\
\hline Managers $^{r}$ & $3.2[3.0-3.4]$ & 1.0 & 1.0 & \\
\hline Middle Executive & $5.3[5.0-5.6]$ & $1.47[1.05-2.06]$ & $1.36[1.00-1.91]$ & 0.07 \\
\hline Clerks & $6.0[5.7-6.3]$ & $1.60[1.17-2.19]$ & $1.37[1.00-1.89]$ & 0.06 \\
\hline Workers & 8.0 [7.7-8.3] & $2.23[1.63-3.05]$ & $2.08[1.51-2.87]$ & $<0.001$ \\
\hline Retired & $8.4[8.0-8.8]$ & $1.50[1.11-2.03]$ & $1.51[1.07-2.12]$ & 0.018 \\
\hline Other non working & 7.2 [6.9-7.5] & $2.05[1.51-2.78]$ & $1.85[1.34-2.56]$ & $<0.001$ \\
\hline \multicolumn{5}{|l|}{ Place of Residence } \\
\hline North & $8.8[8.4-9.2]$ & $1.32[1.04-1.64]$ & $1.30[1.00-1.62]$ & 0.07 \\
\hline East & $6.3[6.0-6.6]$ & $0.92[0.75-1.15]$ & $0.90[0.73-1.12]$ & 0.35 \\
\hline Center & $6.6[6.3-6.9]$ & $1.00[0.88-1.15]$ & $1.00[0.92-1.19]$ & 0.15 \\
\hline West & $7.1[6.8-7.4]$ & $1.17[0.98-1.41]$ & $1.13[0.94-1.36]$ & 0.19 \\
\hline South ${ }^{r}$ & 6.9 [6.6-7.2] & 1.0 & 1.0 & \\
\hline \multicolumn{5}{|l|}{ Community Size } \\
\hline Rural ( $\leq 2000)$ & 7.6 [7.3-7.9] & $1.15[0.95-1.38]$ & 1.09 [0.89-1.34] & 0.21 \\
\hline Cities $<20000$ & $7.3[7.0-7.6]$ & $1.08[0.89-1.33]$ & $1.13[0.93-1.37]$ & 0.40 \\
\hline Cities $<100000^{r}$ & $7.3[7.0-7.6]$ & 1.0 & 1.0 & \\
\hline Cities $>100000$ & 6.9 [6.6-7.2] & $1.00[0.83-1.20]$ & $1.03[0.85-1.24]$ & 0.76 \\
\hline Paris (10 millions) & $5.0[4.7-5.3]$ & $0.72[0.58-0.90]$ & $0.72[0.57-0.93]$ & 0.01 \\
\hline
\end{tabular}

Table 3: Prevalence of chronic pain with neuropathic characteristics according to sociodemographic characteristics. Unadjusted odds ratio and adjusted odds ratio based on forward stepwise logistic regression. ${ }^{r}=$ reference category. 


\begin{tabular}{|c|c|c|}
\hline & $\begin{array}{c}\text { Chronic Pain with } \\
\text { Neuropathic } \\
\text { Characteristics } \\
\%\end{array}$ & $\begin{array}{c}\text { Chronic Pain without } \\
\text { Neuropathic } \\
\text { Characteristics } \\
\%\end{array}$ \\
\hline Mean DN4 score & $3.8 \pm 0.9$ ** & $0.8 \pm 0.7$ \\
\hline $\begin{array}{l}\text { Pain Descriptors } \\
\text { Burning } \\
\text { Painful cold } \\
\text { Electric shock } \\
\text { Tingling } \\
\text { Pins and Needles } \\
\text { Itching } \\
\text { Numbness }\end{array}$ & $\begin{array}{l}67.2^{* * *} \\
22.6^{* * *} \\
63.8^{* * *} \\
54.3^{* * *} \\
73.4^{* * *} \\
20.7^{* * *} \\
74.3^{* * *}\end{array}$ & $\begin{array}{c}17.3 \\
3.7 \\
18.1 \\
7.6 \\
5.5 \\
2.0 \\
24.9\end{array}$ \\
\hline $\begin{array}{l}\text { Mean Pain intensity } \\
\text { Mild (1-3) } \\
\text { Moderate (4-6) } \\
\text { Severe }(7-10)\end{array}$ & $\begin{array}{l}22.7^{\star \star \star} \\
48.7^{25.4^{\star * \star}}\end{array}$ & $\begin{array}{l}39.8 \\
46.4 \\
11.9\end{array}$ \\
\hline $\begin{array}{l}\text { Pain Duration } \\
<6 \text { months } \\
6-12 \text { months } \\
12-36 \text { months } \\
>36 \text { months }\end{array}$ & $\begin{array}{l}9.8^{* *} \\
15.3 \\
25.9 \\
48.7^{* *}\end{array}$ & $\begin{array}{l}14.6 \\
18.2 \\
25.4 \\
41.4\end{array}$ \\
\hline $\begin{array}{l}\text { Pain Locations } \\
\text { Head } \\
\text { Neck/shoulder } \\
\text { Upper Limb } \\
\text { Thorax } \\
\text { Abomen } \\
\text { Back } \\
\text { Lower Limb }\end{array}$ & $\begin{array}{l}8.9 \\
42.9 \\
46.9 \text { ***} \\
8.6 \\
2.3 \\
62.7 \\
71.1^{\star * *}\end{array}$ & $\begin{array}{c}5.6 \\
31.9 \\
25.8 \\
3.5 \\
4.1 \\
58.3 \\
46.6\end{array}$ \\
\hline
\end{tabular}

Table 4: Comparison of the clinical characteristics of chronic pain with or without neuropathic characteristics. ${ }^{* *} p<0.001 ;{ }^{* *} p<0.01$ 


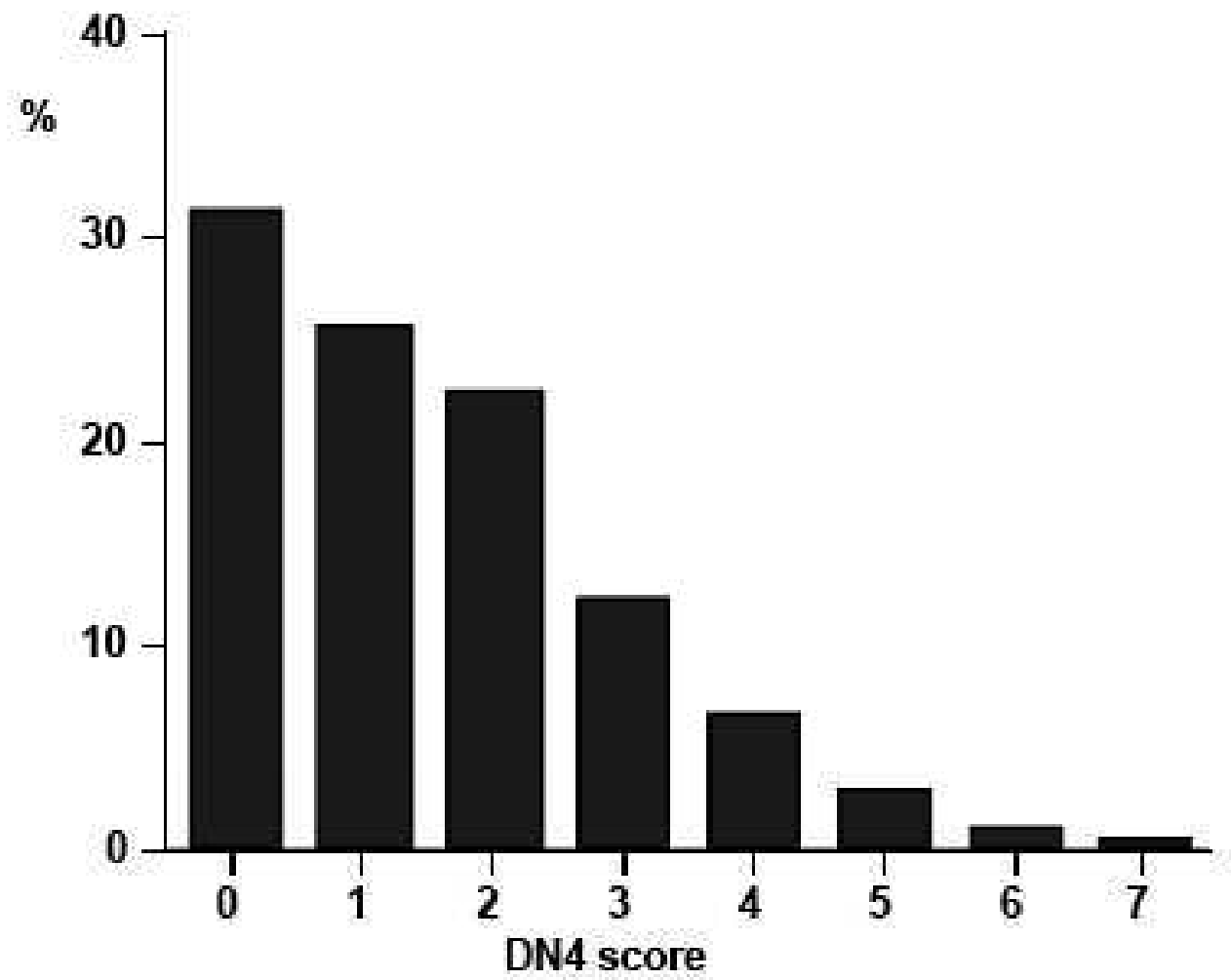

Figure 1: Distribution of the mean DN4 score in the survey respondents. 


\section{References}

Andersen G, Vestergaard K, Ingeman-Nielsen M, Jensen TS. Incidence of central poststroke pain. Pain 1995; 61: 187-93.

Andersson GB. Epidemiological features of chronic low-back pain. Lancet 1999; 354: $581-5$.

Attal N, Cruccu G, Haanpaa M, Hansson P, Jensen TS, Nurmikko T, Sampaio C, Sindrup S, Wiffen P; EFNS Task Force. EFNS guidelines on pharmacological treatment of neuropathic pain. Eur J Neurol. 2006; 13: 1153-1169.

Andersson HI, Ejlertsson G, Leden I, Rosenberg C. Chronic pain in a geographically defined general population: studies of differences in age, gender, social class, and pain localization. Clin J Pain 1993; 9: 174-82.

Backonja MM. Defining neuropathic pain. Anesth Analg. 2003; 97: 785-790.

Baron R. Mechanisms of disease: neuropathic pain - a clinical perspective. Nature Clin Pract Neurol 2006; 2: 95-106.

Bennett GJ. Neuropathic pain: a crisis of definition? Anesth Analg. 2003; 97: 619-620.

Bennett M, Attal N, Backonja M, Baron R, Bouhassira D, Freynhagen R, Scholtz J, Tolle T, Wittchen HU, Jensen TS, Using screening tools to identify neuropathic pain. Pain, 2007, 127: 199-203.

Bennett M. The LANSS Pain Scale: the Leeds assessment of neuropathic symptoms and signs. Pain 2001; 92: 147-57.

Blyth FM, March LM, Brnabic AJ, Jorm LR, Williamson M, Cousins MJ. Chronic pain in Australia: a prevalence study. Pain 2001; 89: 127-34. 
Bouhassira D, Attal $\mathrm{N}$, Alchaar $\mathrm{H}$, et al. Comparison of pain syndromes associated with nervous or somatic lesions and development of a new neuropathic pain diagnostic questionnaire (DN4). Pain 2005; 114: 29-36.

Boureau F, Doubrere JF, Luu M. Study of verbal description in neuropathic pain. Pain 1990; 42: 145-52.

Bowsher D. Neurogenic pain syndromes and their management. Br Med Bull 1991; 47: 644-66.

Breivik H, Collett B, Ventafridda V, Cohen R, Gallacher D. Survey of chronic pain in Europe: Prevalence, impact on daily life, and treatment. Eur J Pain 2006; 10: 287-333.

Buskila D, Abramov G, Biton A, Neumann L. The prevalence of pain complaints in a general population in Israel and its implications for utilization of health services. J Rheumatol 2000; 27: 1521-5.

Caraceni A, Portenoy RK. An international survey of cancer pain characteristics and syndromes. IASP Task Force on Cancer Pain. International Association for the Study of Pain. Pain 1999; 82: 263-74.

Cleeland CS, Ryan KM. Pain assessment: global use of the Brief Pain Inventory. Ann Acad Med Singapore 1994; 23: 129-38.

Daousi C, MacFarlane IA, Woodward A, Nurmikko TJ, Bundred PE, Benbow SJ. Chronic painful peripheral neuropathy in an urban community: a controlled comparison of people with and without diabetes. Diabet Med 2004; 21: 976-82.

Davies HTO, Crombie IK, Macrae WA, Rogers KM. Pain clinic patients in northern Britain. The Pain Clinic 1992; 5: 129-35. 
Davies M, Brophy S, Williams R, Taylor A. The prevalence, severity, and impact of painful diabetic peripheral neuropathy in type 2 diabetes.Diabetes Care. 2006; 29: 1518-1522.

Davies M, Brophy S, Williams R, Taylor A. The prevalence, severity, and impact of painful diabetic peripheral neuropathy in type 2 diabetes.Diabetes Care. 2006; 29: 1518-22.

Deville JC, Sarndal CE, Sautory O. Generalized raking procedures in survey sampling. J Am Statist Assoc 1993; 88: 1013-20.

Deyo RA, Weinstein JN. Low back pain. N Engl J Med 2001; 344: 363-70.

Dworkin $\mathrm{RH}$, Backonja $\mathrm{M}$, Rowbotham $\mathrm{MC}$, et al. Advances in neuropathic pain: diagnosis, mechanisms, and treatment recommendations. Arch Neurol 2003; 60:1524-34.

Elliott AM, Smith BH, Penny KI, Smith WC, Chambers WA. The epidemiology of chronic pain in the community. Lancet 1999; 354: 1248-52.

Eriksen J, Jensen MK, Sjogren P, Ekholm O, Rasmussen NK. Epidemiology of chronic non-malignant pain in Denmark. Pain 2003; 106: 221-8.

Finnerup NB, Otto M, McQuay HJ, Jensen TS, Sindrup SH. Algorithm for neuropathic pain treatment: an evidence based proposal. Pain 2005; 118: 289-305.

Freynhagen $\mathrm{R}$, Baron $\mathrm{R}$, Gockel $\mathrm{U}$, Tolle TR. painDETECT: a new screening questionnaire to identify neuropathic components in patients with back pain. Curr Med Res Opin. 2006a; 22: 1911-1920.

Freynhagen R, Baron R, Tolle T, Stemmler E, Gockel U, Stevens M, Maier C. Screening of neuropathic pain components in patients with chronic back pain associated with nerve root compression: a prospective observational pilot study (MIPORT). Curr Med Res Opin 2006b; 22: 529-37. 
Grond S, Zech D, Diefenbach C, Radbruch L, Lehmann KA. Assessment of cancer pain: a prospective evaluation in 2266 cancer patients referred to a pain service. Pain 1996; 64: 107-14

Hansson P. Neuropathic pain: clinical characteristics and diagnostic workup. Eur J Pain. 2002; 6: 47-50.

Harden N, Cohen M. Unmet needs in the management of neuropathic pain. J Pain Symptom Manage 2003; 25(5 Suppl): S12-7.

Hewitt DJ, McDonald M, Portenoy RK, Rosenfeld B, Passik S, Breitbart W. Pain syndromes and etiologies in ambulatory AIDS patients. Pain 1997; 70: 117-23.

Hillman M, Wright A, Rajaratnam G, Tennant A, Chamberlain MA. Prevalence of low back pain in the community: implications for service provision in Bradford, UK. J Epidemiol Community Health 1996; 50: 347-52.

Institut National des Statistiques et des Etudes Economiques (INSEE). Enquête sur l'emploi, March 2002. Society Detailed Results 2002, 5: 1-50.

Irving GA. Contemporary assessment and management of neuropathic pain.Neurology. 2005; 64 (Suppl 3): S21-S27.

Jensen TS, Baron R. Translation of symptoms and signs into mechanisms in neuropathic pain. Pain 2003; 102: 1-8.

Jung BF, Johnson RW, Griffin DR, Dworkin RH. Risk factors for postherpetic neuralgia in patients with herpes zoster. Neurology. 2004; 62: 1545-155.

Kaki AM, El-Yaski AZ, Youseif E. Identifying neuropathic pain among patients with chronic low-back pain: use of the Leeds Assessment of Neuropathic Symptoms and 
Signs pain scale. Reg Anesth Pain Med 2005; 30: 422-8.

Kehlet $\mathrm{H}$, Jensen TS, Woolf CJ. Persistent postsurgical pain: risk factors and prevention. Lancet. 2006; 367: 1618-1625.

Krause SJ, Backonja MM. Development of a neuropathic pain questionnaire. Clin J Pain 2003;19(5):306-14.

Max MB. Clarifying the definition of neuropathic pain. Pain 2002; 96: 406-407.

Osterberg A, Boivie J, Thuomas KA. Central pain in multiple sclerosis--prevalence and clinical characteristics. Eur J Pain 2005; 9: 531-42.

Portenoy RK. Development and testing of a neuropathic pain screening questionnaire: ID Pain. Curr Med Res Opi, 2006; 8: 1555-1565.

Rasmussen PV, Sindrup SH, Jensen TS, Bach FW. Symptoms and signs in patients with suspected neuropathic pain. Pain 2004; 110: 461-469.

Rustoen T, Wahl AK, Hanestad BR, Lerdal A, Paul S, Miaskowski C. Prevalence and characteristics of chronic pain in the general Norwegian population. Eur J Pain 2004; 8: $555-65$.

Siddall PJ, McClelland JM, Rutkowski SB, Cousins MJ. A longitudinal study of the prevalence and characteristics of pain in the first 5 years following spinal cord injury. Pain 2003; 103: 249-57.

Torrance N, Smith BH, Bennett Ml, Lee AJ. The epidemiology of chronic pain of predominantly neuropathic origin. Results from a general population survey. J Pain 2006; 7: $281-9$.

Verhaak PF, Kerssens JJ, Dekker J, Sorbi MJ, Bensing JM. Prevalence of chronic benign 
pain disorder among adults: a review of the literature. Pain 1998; 77: 231-9.

Webb R, Brammah T, Lunt M, Urwin M, Allison T, Symmons D. Prevalence and predictors of intense, chronic, and disabling neck and back pain in the UK general population. Spine 2003; 28: 1195-202.

Woolf $\mathrm{CJ}$, Mannion RJ. Neuropathic pain: aetiology, symptoms, mechanisms, and management. Lancet 1999; 353: 1959-64.

Woolf CJ. Pain: moving from symptom control toward mechanism-specific pharmacologic management. Ann Intern Med 2004; 140: 441-51. 